EL “LUGAR” DE LA INTERPRETACIÓN CONFORME CON EL CEDH EN EL ORDENAMIENTO ITALIANO

\title{
CORRADO CARUSO
}

Profesor de Derecho constitucional de la Universidad de Bolonia y Letrado en la Corte Constitucional 


\section{Resumen}

El trabajo hace un estudio de la interpretación convencionalmente orientada y su conexion con la interpretación conforme en el ordenamiento italiano, estudiando sus límites estructurales y axiológicos. Asimismo, se ocupa de las relaciones entre el ordenamiento constitucional italiano y el convencional.

Palabras clave: Convenio Europeo de Derechos Humanos, interpretación conforme, interpretación convencionalmente orientada

\section{The "place" of the interpretation in conformity with the ECHR in the Italian legal order}

\section{Abstract}

This essay studies the interpretation in conformity with the ECHR and its connection with the interpretation in conformity with the Constitution the Italian legal order, analyzing its structural and axiological limits. Likewise, the study deals with the relationships between the italian constitutional order and the conventional order.

Palabras clave: European Convention of Human Rights, Interpretation in conformity with the convention 
SUMARIO': I. LA INTERPRETACIÓN CONFORME: ¿QUÉ ES? II. EL ESTATUTO CONSTITUCIONAL DE LA INTERPRETACIÓN CONVENCIONALMENTE ORIENTADA. LOS LÍMITES ESTRUCTURALES. 1. El texto. 2. La unidireccionalidad de la interpretación convencionalmente orientada. El "peso" de la jurisprudencia del TEDH. III. EL LÍMITE AXIOLÓGICO. LA NATURALEZA RESIDUAL Y RECESIVA DE LA INTERPRETACIÓN CONVENCIONALMENTE ORIENTADA. IV. MUNDOS PARALELOS: EL ORDENAMIENTO CONSTITUCIONAL Y EL ORDENAMIENTO CONVENCIONAL COMPARADOS. V. BIBLIOGRAFÍA

\section{LA INTERPRETACIÓN CONFORME: ¿QUÉ ES?}

La interpretación conforme tiene una dimensión anfibia ${ }^{3}$ : por un lado es un topos hermenéutico, un particular argumento persuasivo que nos da razones para justificar un determinado resultado interpretativo; por otro lado, es una regla sobre la interpretación o sobre cómo interpretar, canon preceptivo que indica el procedimiento a seguir para la adscripción de significado a una determinada disposición.

En cuanto a este último perfil, se ha sostenido, con diferentes matices, que la interpretación conforme no sería más que una species de la interpretación sistemática, porque respondería, como esta última, al postulado general de coherencia del ordenamiento jurídico que el intérprete está llamado a satisfacer en su actividad ordinaria ${ }^{4}$.

Esta tesis no puede ser acogida plenamente. La interpretación lógico-sistemática tiene una génesis estrechamente ligada a la hermenéutica codicística, debiendo operar con respecto a normas situadas en el mismo acto jurídico (incluso si se descifran a la luz del ordenamiento considerado en su totalidad $)^{5}$, mientras que la interpretación conforme presupone (aunque se volverá sobre este punto) una relación jerárquica entre fuentes ${ }^{6}$. A pesar de ello, el acercamiento a la interpretación sistemática evidencia oportunamente la función relacional de la interpretación adecuadora, capaz de conectar actos y sistemas

\footnotetext{
*Traducido del italiano por Germán M. Teruel Lozano.

${ }^{3}$ Cfr. BIN, R., 'L'interpretazione conforme. Due o tre cose che so di lei', en BERNARDI, A. (ed.), L'interpretazione conforme al diritto dell'unione europea. Profili e limiti di un vincolo problematico, Nápoles, 2015, pp. 17 y ss., de forma similar EPIDENDIO, T., ''Riflessioni teorico-pratiche sull'interpretazione conforme', Dir. pen. cont., n.3-4,2012, pp. 26 y ss.

${ }^{4}$ En este sentido, BIN, R., ''L'interpretazione conforme... cit.', pp. 17-19, y en el mismo sentido RUGGERI, A., ' 'L'interpretazione conforme e la ricerca del "sistema di sistemi" come problema', en L'interpretazione conforme ... cit., pp.153-158.

${ }^{5}$ En esta dirección me parece que van la observación aquí compartida de EPIDENDIO, T., '’Riflessioni....cit.', pp. 26-27.

${ }^{6}$ BERNARDI, A., 'Presentazione, Nei meandri dell'interpretazione conforme al diritto dell'Unione europea', en L'interpretazione conforme... cit., p. XIII.
} 
normativos diversos, que a menudo responden a lógicas y rationes distintas pero igualmente relevantes para la aplicación de una determinada disposición ${ }^{7}$. Como se ha dicho la interpretación conforme es así una bisagra que une armoniosamente mundos normativos distintos pero unidos por la necesidad de ofrecer soluciones al caso controvertido ${ }^{8}$.

Para diseñar los perfiles de la interpretación conforme hay que partir, como se ha dicho, de una relación jerárquica entre fuentes. «[O]bligación de medios» ${ }^{9}$ que pesa sobre el intérprete, llamado a extrapolar de la disposición un significado normativo coherente con las normas de otra fuente que se colocan, respecto de la primera, «en una específica relación condicionante» ${ }^{10}$, la interpretación conforme no coincide con los criterios adoptados por el ordenamiento para resolver las antinomias normativas $\mathrm{y}$, en consecuencia, ordenar las fuentes del Derecho en el sistema ${ }^{11}$. A menos que no se avale la hipótesis, con un vago sabor realista, de la reducción del sistema de fuentes al concreto resultado interpretativo, a la norma dictada por las contingencias del caso concreto (inevitablemente influída, por tanto, por la peculiar Weltanschauung del intérprete), los criterios de resolución de las antinomias normativas son externos a la activdad interpretativa, determinados por el ordenamieto jurídico y no creados por el sujeto interpretante ${ }^{12}$.

La interpretación conforme introduce, por tanto, una triple operación hermenéutica consecuente con la relación jerárquica entre las fuentes: la primera realizada sobre el enunciado supraordenado, la segunda sobre la disposición condicionada, ambas sometidas, al final, a una "soldadura" normativa con vistas en la decisión final

En estos términos, la interpretación conforme baña las fronteras de la aplicación directa de la fuente superior: importa poco establecer si esta útima se eleva como fuente inmediata de la regla del caso concreto o si representa la premisa mayor del razonamiento

\footnotetext{
${ }^{7}$ Subraya este aspecto RUGGERI, A., ' 'L'interpretazione conforme...cit.', pp. 156-157.

${ }^{8}$ LAMARQUE, E., ' 'Le relazioni tra l'ordinamento nazionale, sovranazionale e internazionale nella tutela dei diritti’, en Dir. pubbl. 2013, p.788.

${ }^{9}$ Celotto, A., Pistorio, G. Interpretazioni comunitariamente e convenzionalmente conformi, Giur. it. 2010, p. 1980.

${ }^{10}$ LUCIANI, M., 'Interpretazione conforme a Costituzione', Enc. dir., Ann., IX, Milán, 2016, p. 445.

${ }^{11}$ Contra, sin embargo, LuCIANI, M., ' 'Interpretazione conforme...cit.', p. 442 y ss.

${ }^{12}$ V. por el contrario lo sostenido por RUGGERI, A., 'Lo Stato costituzionale e le sue mutazioni genetiche', Quad. cost., 2014, p.845 y ss., el cual propone convertir la teoría de las fuentes en una teoría axiológicamente orientada de las normas. En sentido similar, v. BIN, R., ''Ordine delle norme e disordine dei concetti (e viceversa). per una teoria quantistica delle fonti del diritto', en BRUnElli, G., PUGIOTTO, A., VeroneSI, P., Scritti in onore di Lorenza Carlassare. Il diritto costituzionale come regola e limite al potere, vol. I., Nápoles, 2009, pp. 35 y ss. En opinión de este autor, el único dique al poder iusgenerativo del juez vendría dado por el vínculo del precedente.
} 
normativo $^{13}$. Lo que evidencia es la función nomogenética que desarrolla, en vía interpretativa, la fuente supraordenada, la cual, iluminando la fuente subordinada, expresa su supremacía sobre el material normativo subyacente.

A la luz de estas premisas, dos son los indiscutibles protagonistas de la interpretación conforme: la fuente superior, que amplifica su preceptividad y permea el sistema normativo; el intérprete (normalmente, como se verá, el juez ordinario), que encuentra en aquella un yacimiento preceptivo que le permite extraer, de los actos-fuentes subyacentes, significados que no sería posible alcanzar mediante los tradicionales cánones hermenéuticos.

Estas consideraciones se han ido definiendo en relación con la interpretación conforme a la Constitución, que ha servido de prototipo y modelo de las sucesivas interpretaciones conformes desarrolladas con referencia, en particular, al ordenamiento comunitario y al sistema convencional.

La interpretación conforme a la Constitución ha representado, en efecto, el enlace de conexión entre dos sistemas normativos que, en la intención de los Constituyentes ${ }^{14}$, debían permanecer rigurosamente diferenciados: por un lado, la Constitución y el circuito de la legalidad constitucional, custodiados por la Corte Constitucional; y, por otro, el ámbito de la legalidad ordinaria, dominado por la ley, atribuido a los jueces comunes ${ }^{15}$. Es la propia Corte Constitucional la que, después de su aparición en la escena republicana, ha utilizado este canon, dando vida a la tipología decisoria de las sentencias interpretativas (de rechazo) ${ }^{16}$. En las décadas siguientes, las conocidas vicisitudes sobre el 36 Cost. $^{17}$, que

\footnotetext{
${ }^{13}$ Cfr., BIN, R., 'L'applicazione diretta della Costituzione, le sentenze interpretative, l'interpretazione conforme della Costituzione alla legge", en La circolazione dei modelli e delle tecniche del giudizio di costituzionalità in Europa: Atti del XXI Convegno annuale, Roma 27-28 ottobre 2006:50 anniversario della Corte Costituzionale della Repubblica Italiana, Nápoles, 2010, p. 221. Para una opinión en parte distinta, dirigida a distinguir entre aplicación directa e interpretación conforme a la Constitución, CHESSA, O., 'Drittwirkung e interpretazione: brevi osservazioni su un caso emblematico', en MALFATTI, E., Rombol, R., Rossi, E. (ed.), Il giudizio sulle leggi e la sua 'diffusione, Turín, 2002, pp. 420 y ss., 425.

${ }^{14}$ Cfr. las conocidas tesis de MezZAnotTe, C., Il giudizio sulle leggi, I, Le ideologie del Costituente, Nápoles, 2014, pp.196-197.

${ }^{15} \mathrm{O}$, como vino a decir el primer presidente de la Corte Constitucional, Enrico De Nicola, por un lado la Corte Constitucional, vestal de la Constitución, por otro la Magistratura, vestal de la ley. La referencia se encuentra en GAETA, P., "Controllo di convenzionalità" e poteri del giudice nazionale: $i$ difficili approcci dell'ermeneutica giudiziale, draft, 9.

${ }^{16} \mathrm{Cfr}$. la conocida Sent. Cort. Cost. 8/1956, sobre la extensión de los poderes de los prefectos previstos por el art. 2 del TULPS.

${ }^{17} \mathrm{La}$ referencia, contenida en el art. art. 36 Cost. it., a la necesidad de una retribución suficiente y proporcionada al trabajo prestado ha permitido a la Corte de Casación establecer la eficacia erga omnes del quantum salarial indicado en el contrato colectivo nacional (en ausencia del desarrollo del art. 39 Const. It.). Referencias en BARTOLE, S., Interpretazioni e trasformazioni della Costituzione repubblicana, Bolonia, 2004, pp.166 y ss.
} 
inauguraron la práctica judicial de la aplicación directa de la Constitución y la relevancia, atribuida por el Juez de las leyes, al intento de interpretación adecuadora de la disposición impugnada por parte del juez a quo (con pena de inadmisibilidad de la cuestión de inconstitucionalidad) ${ }^{18}$, confirman la compenetración de los sistemas normativos y evidencian el nuevo rol asumido por el juez ordinario el cual, en la aplicación de las disposiciones legales, debe adecuar su sentido a la Norma Fundamental.

Por un lado, en efecto, la Constitución se impone sobre el sistema normativo subordinado, a través de la aplicación difusa que encuentra su único límite en la absoluta incompatibilidad de la interpretación correctiva con la letra del texto de la ley; por otro lado, el juez ordinario, como simple portero de la Corte Constitucional, según la feliz imagen de Piero Calamandrei, se eleva a garante y promotor de los principios constitucionales. Los jueces (sobre todo los ordinarios) dejan de ser asepticos exégetas de la ley para convertirse en protagonistas de la realización de los valores constitucionales en

\footnotetext{
${ }^{18}$ A partir de la célebre Sent. Cort. Cost. 356/1996 decisión que, según algunos (ad es., RomboLI, R., 'Il giudizio di costituzionalità delle leggi", en ID. (ed.), Aggiornamenti in tema di processo costituzionale (1996-1998), Turín, 1999,p.202, contra RuOTOLO, M., 'Interpretazione conforme a Costituzione e tecniche decisorie della Corte costituzionale", en AA.Vv., Scritti in onore di Alessandro Pace, Nápoles, 2012, p. 2478) habría introducido una ulterior condición de admisibilidad de la q.l.c. Esta conclusión podría reconsiderarse a la luz de la jurisprudencia constitucional más reciente, la cual no sanciona con la inadmisibilidad la cuestión propuesta por el remitente que no presente posibles interpretaciones adecuadoras de la disposición censurada (cfr. Sents. Cort. Const. 77/2018, 83/2017, y 221/2015) o, al menos, cuando «sia improbabile o difficile prospettarne un'interpretazione costituzionalmente orientata» (Sent. Cort. Cost. 42/2017). Esta orientación tiende a ampliar la admisibilidad y, por tanto, las posibilidades de conocer del Juez Constitucional, retomando cuanto ya se ha dicho, en sede científica, sobre la última decisión citada (cfr. ModuGNO, F., 'Sul problema dell'interpretazione conforme a Costituzione: un breve excursus", Giur. it., 2010, 1963, en el mismo sentido SERGES, G., 'Interpretazione conforme e tecniche processuali', ivi, 19771978). Los dicta que se acaban de mencionar recuperan la actualidad de la tesis de aquella doctrina que consideraba excepcional la operativida de la interpretación adecuadora, sobre la base de la consideración de que la "regla" del control de constitucionalidad fuera la de "evitar cualquier aplicación inconstitucional". Esta tarea fundamental de "profilasi" constitucional, ínsita en el control concentrado de constitucionalidad, debería inducir a la Corte Constitucional a un juicio de fondo, y a acoger las cuestiones propuestas allí donde el texto exprese aunque sólo sea una norma contraria a la Constitución (así PACE, A., "I limiti dell'interpretazione «adeguatrice»", Giur. Costit., 1963, pp. 1070-1073). El Constitucional, por ello, tendría que adoptar sentencias interpretativas de estimación, decisiones en las que, aunque tuvieran como objeto normas, proyecten sus efectos también sobre las disposiciones (en este sentido siempre PACE, A., 'Identità o differenza tra la questione di costituzionalità della norma e la questione di costituzionalità dell'interpretazione?', Giur. Costit., 1965, pp.1650 ss., comentando las sentencias de la Corte de Casación, s. u., n. 666 de 1965). En opinión de esta reconocida doctrina, la elección por este tipo de decisiones haría justicia a la posición institucional de la Corte Constitucional, que de otra forma quedaría degradada como un mero sucedáneo del Tribunal Supremo (cfr. PACE, A., 'Sul dovere della Corte costituzionale di adottare sentenze di accoglimento (se del caso, «interpretative» e «additive») cuando la inconstitucionalidad se encuentre en la «letra» de la dispoción, nota crítica a Corte cost. sent. n. 343 de 2006 sobre la que, por otro lado, puede verse Ruotolo, M., 'Per una gerarchia degli argomenti dell'interpretazione", ambas en Giur. Costit., 2006, respectivamente, pp. 3430-3431, 3418 y ss).
} 
el ordenamiento jurídico y, según algunas reconstrucciones, incluso co-titulares de la función de dirección político-constitucional ${ }^{19}$.

\section{EL ESTATUTO CONSTITUCIONAL DE LA INTERPRETACIÓN CONVENCIONALMENTE ORIENTADA. LOS LÍMITES ESTRUCTURALES.}

\section{El texto.}

La interpretación convencionalmente orientada nace casi por gemación de la interpretación constitucionalmente conforme, llevando a un camino no muy distante del recorrido por la interpretación conforme al Derecho comunitario (en relación con la normativa europea non self executing, para asegurar el "efecto útil") ${ }^{20}$. Son técnicas que permiten al juez ordinario entrar en contacto con las jurisdicciones externas, las cuales operan según principios y lógicas de funcionamiento no del todo superponibles a las de los ordenamientos nacionales ${ }^{21}$.

Es la Corte Constitucional, en las sentencias n. 348 y 349 de 2007 (conocidas como las 'sentencias gemelas'), la que extrae, como consecencia del renovado rango interpuesto del $\mathrm{CEDH}$, el canon de interpretación convencionalmente orientada. Pero, como se verá, precisamente la particular naturaleza del Convenio y su posición en el ordenamiento interno diluyen la fuerza del ámbito preceptivo de dicho canon. La jurisprudencia constitucional, de hecho, ha vaciado progresivamente este criterio hermenéutico, el cual ha perdido la función de regla sobre la interpretación para asumir los rasgos, menos disruptivos, de simple argumento interpretativo. Sobre este punto se volverá: por el momento basta anticipar que la tenue fuerza preceptiva de la interpretación convencionalmente orientada determina la especialidad y, sobre todo, la irreductibilidad

\footnotetext{
${ }^{19}$ Como se vino a sostener en el congreso celebrado en Gardone Riviera en 1965, en el año sucesivo a la fundación de la Magistratura Democratica, MARANINI, G., ''Funzione giurisdizionale e indirizzo politico nella Costituzione", en Rass. parl., 1965, pp. 538 y ss. Sobre esta cuestión v. también SORRENTI, G., L'interpretazione conforme a Costituzione, Milán, 2006, p. 111, que considera que la interpretación conforme a la Constitución es un "criterio organizativo" que implica una función de armonización, desarrollada por el juez ordinario, del ordenamiento jurídico.

${ }^{20}$ Por primera vez explícitamente, Sent. Cort. Cost. 190/2000. Sobre esta cuestión BARBERA, A., “Costituzione della Repubblica italiana", en Enc. dir., ann. VIII, Milán, 2015, p. 323.

${ }^{21}$ Así GuAZZAROTTI, A., ' 'Interpretazione conforme alla CEDU, proporzionalità e adeguatezza: il diritto di proprietà', en M. D'AMICO, B. RANDAZZO (ed.), Interpretazione conforme e tecniche argomentative, Atti del convegno di Milano svoltosi il 6-7 giugno 2008, Turín, 2009,p. 162.
} 
respecto a los otros procedimientos interpretativos "de conformidad" (de forma especial, a la interpretación conforme a la Constitución).

Con la sentencia n. 348 de 2007, como es sabido, la Corte Constitucional ha dictado las coordenadas de la relación entre legislación ordinaria y Convenio Europeo de los Derechos Humanos. En virtud de la referencia, contenida en el art. 117.1 Const., a las obligaciones internacionales, este tratado (rectius: su ley de ejecución) se considera fuente interpuesta entre la Constitución y la legislación inferior. De esta relación jeárquica se deduce un necesario vínculo de adecuación de la ley al Convenio, como se aprecia en la jurisprudencia del TEDH, puesto que «la comprobación de la compatibilidad constitucional debe dirigirse a la norma [convencional] como producto del intérprete, no a la disposición in sé e per sé considerada» ${ }^{22}$.

De la supraordenación del CEDH con respecto a la ley deriva un nuevo vínculo interpretativo para el juez ordinario, llamado a traducir la relación jerárquica entre fuentes en una soldadura normativa entre precepto internacional y significados deducibles de la disposición legislativa. Sólo en caso de «contradicción no resolvible en vía interpretativa entre la norma censurada y las normas del CEDH, tal y como son interpretadas por el TEDH y asumidas como fuentes integradoras del parámetro de constitucionalidad de acuerdo con el art. 117.1 Const.», se puede activar el control de legitimidad constitucional $^{23}$. La sentencia n. 349 de 2007 aclarará posteriormente este pasaje: al juez común «corresponde interpretar la norma interna de forma conforme con las disposiciones internacionales, dentro de los límites que le sean permitidos por los textos de las normas [cursiva añadida]» ${ }^{24}$, recurriendo «a todos los instrumentos de hermenéutica jurídica» ${ }^{25}$; «allí donde esto no sea posible, o se dude de la compatibilidad de la norma interna con la disposición convencional 'interpuesta', este Tribunal debe asumir la correspondiente cuestión de legitimidad constitucional con respecto al parámetro del art. $117.1 »^{26}$.

Las llamadas sentencias gemelas inauguran una orientación jurisprudencial que compondrá un breviario de las propiedades estructurales de la interpretación

\footnotetext{
${ }^{22}$ Sent. Cort. Cost. 348/2007. Es evidente la influencia en esta impostación de la distinction crisafulina entre norma y disposición, sobre la cual CRISAFULLI, V., 'Disposizione (e norma)", en Enc. dir., vol. XII, Milán, 1964, pp.195 y ss.

${ }^{23}$ Sent. Cort. Cost. 348/2007.

${ }^{24}$ Sent. Cort. Cost. 349/2007.

${ }^{25}$ Sent. Cort. Cost. 293/2009, en este mismo sentido Sents. Cort. Cost. 331/2009 y 93/2010.

${ }^{26}$ Sent. Cort. Cost. 349/2007.
} 
convencionalmente orientada, las cuales identifican otros tantos límites a su concreta operatividad.

En primger lugar, el límite del texto: ninguna interpretación puede superar el escollo de la littera legis, ningún procedimiento de adscripción de sentido a la disposición puede llegar a manipular el enunciado lingüístico hasta traducirse en una heurística normativa contra legem. Se trata de un límite lógico, intrínseco a esta técnica interpretativa, necesario no sólo para distinguir el criterio en palabras de la hipótesis, teóricamente contigua, «de la inaplicación de la norma interna contradictoria con la norma internacional» ${ }^{27}$, sino también -y sobre todo- para evitar que el Convenio pueda dar lugar a efectos directos.

La cuestión, de importancia fundamental, lleva a distinguir la interpretación convencionalmente orientada de la interpretación conforme a la Constitución. Mientras, en efecto, esta última es instrumental para permitir la aplicación directa de la Constitución, y por tanto para proyectar los valores y los principios constitucionales en el sistema normativo inferior, no se puede decir lo mismo en relación con las fuentes internacionales, capaces de vincular al legislador ordinario pero en todo caso sometidas a la protección de la Constitución y de cualquier manifestación preceptiva de ésta ${ }^{28}$.

El vínculo del texto provoca efectos distintos según si la disposición es interpretada a la luz de la Constitución o del Convenio; mientras que en el primer caso será posible realizar una concretización normativa de la Constitución hasta el límite último de la inaplicación del texto legislativo (capaz de frustrar la función del control concentrado de legitimidad constitucional), en la segunda hipótesis la interpretación convencionalmente orientada deberá detenerse en la frontera de la aplicación directa del Convenio. En otras palabras, el rango interpuesto es, en este caso, fundamento y límite de las normas del CEDH: la subordinación formal a la Constitución no permite el efeto directo convencional y, por tanto, el poder «del juez nacional de aplicarlo directamente en lugar de las normas internas en conflicto con el mismo» ${ }^{29}$.

\footnotetext{
${ }^{27}$ Así VIGANÒ, F., 'Il giudice penale e l'interpretazione conforme alle norme sovranazionali', en CORSO, P., ZANETTI, E., Diritto processuale penale e profili internazionali. Diritto straniero e diritto comparato, en Studi in onore di Mario Pisani, Plasencia, 2010, p. 649.

${ }^{28}$ Sent. Cort. Cost. 348/2007.

${ }^{29}$ Cfr. Sent. Cort. Cost. 349/2007, aunque la afirmación es constante. V. en particular Sent. Cort. Cont. 80/2011, donde la Corte aclara el "lugar" del CEDH en el Derecho interno, también en relación con la diferente relación que la primera mantiene con el Derecho comunitario, o la Sent. Cort. Const. 113/2011, que ha introducido una hipótesis específica de revisión de la cosa juzgada penal en caso de violación de los principios convencionales del juzto proceso (adecuando así el ordenamiento interno a la condena de restitutio ad integrum dictada por el TEDH) o, al menos indirectamente, por la Sent. Cort. Const. 123/2017 que ha excluido la revisión de la cosa juzgada civil o administrativa en caso de lesión del art. 6 CEDH.
} 


\section{La unidireccionalidad de la interpretación convencionalmente orientada.}

\section{El "peso" de la jurisprudencia del TEDH.}

Se puede ir más allá. La peculiaridad institucional del CEDH viene dada por la existencia de una institución jurisdiccional de resolución de las controversias que, en su actividad interpretativa de las disposiciones del Convenio, edifica una barrera ulterior a la actividad hermenéutica del juez nacional. Éste, de hecho, no puede anteponer la propia lectura del tratado a la dada por los jueces de Estrasburgo.

Es cierto que al juez nacional le corresponde la posibilidad de recabar, de acuerdo con el Tratado, argumentos persuasivos con el objeto de la mejor tutela de los derechos fundamentales, pero es al TEDH a quien corresponde la «definitiva uniformidad aplicativa» del Derecho convencional ${ }^{30}$. De lo cual se deduce que, a diferencia de la interpretación constitucionalmente conforme, que permite al juez ordinario plasmar, al menos indirectamente, el significado de los enunciados constitucionales, la interpretación convencionalmente orientada es unidireccional, en el sentido de que el procedimiento interpretativo opera sólo en relación con la ley. En otros términos, el juez nacional (común y constitucional) es receptor de la actividad hermenéutica dirigida, «de acuerdo con los cánones hermenéuticos vigentes en el ordenamiento de proveniencia» ${ }^{31}$, por la jurisdicción internacional $^{32}$.

Como consecuencia, el juez ordinario no es competente para controlar en cuanto al fondo el derecho viviente convencional, pudiendo, como mucho, reevaluar las condiciones de admisibilidad de la cuestión de legitimidad constitucional planteada en caso de novum jurisprudencial. A esta posibilidad alude la Corte Constitucional cuando, a partir del auto n. 150 de 2012, ha devuelto los autos al juez a quo para que valorara la influencia sobre la disposición cuestionada de una nueva orientación fijada por el TEDH (en particular, por la Gran Cámara) ${ }^{33}$.

\footnotetext{
${ }^{30}$ Sent. Cort. Const. 349/2007.

${ }^{31}$ VigANÒ, F., 'Il giudice penale...cit',., p. 634.

${ }^{32}$ Sobre esta cuestión cfr. también GAETA, P., Controllo di convenzionalità....cit., p.10.

${ }^{33}$ Principio confirmado, recientemente, por la Sent. Cort. Cost. 43/2018, con referencia al ne bis in idem procesal, sobre la cual v. los comentarios de BINDI, E., 'Divieto di bis in idem e doppio binario sanzionatorio nel dialogo tra giudici nazionali e sovranazionali', en Federalismi.it, 17/2018, y, PEPE, F., 'La Corte costituzionale prende atto della metamorfosi del ne bis in idem europeo: fine della storia?', TRIPODO, A.F., "'Il nuovo volto del ne bis in idem convenzionale agli occhi del giudice delle leggi. Riflessi sul doppio binario sanzionatorio in materia fiscale", y ROMBOLI, R., "'Vincolatività della interpretazione della Cedu da parte della Corte Edu e restituzione degli atti al giudice "a quo" in una pronuncia che mostra la difficile
} 
La subordinación funcional del juez nacional a los dicta de Estrasburgo, sin embargo, no opera automáticamente en modo tal de hacerlo «pasivo receptor de un mandato exegético dictado en algún otro lugar de las formas de la decisión jurisdiccional, cualesquiera que sean las condiciones que lo han determinado ${ }^{34}$. En este sentido, si un juez nacional vuelve a ocuparse del caso decidido por Estrasburgo, las jurisdicciones internas tienen el poder-deber de situar la decisión del TEDH en el flujo de la jurisprudencia convencional, quedando vinculadas al mismo sólo en el caso de derecho jurisprudencial consolidado ${ }^{35} \mathrm{o}$ de sentencias piloto $^{36}$.

A pesar de las críticas recibidas por esta decisión ${ }^{37}$, , considerada por algunos emblema de un «nacionalismo constitucional exasperado» ${ }^{38}$, la Corte Constitucional se ha limitado a especificar las condiciones para que el TEDH cumpla con su función nomofiláctica con respecto a los jueces nacionales, identificando, en otros términos, los requisitos mínimos para la formación, en el Derecho interno, del derecho viviente convencional ${ }^{39}$. En este sentido, la misma no lleva -o lo hace sólo en parte- a que conceptos o instituciones utilizadas por la Corte Constitucional asuman, en el ordenamiento convencional, un significado distinto $^{40}$ : el objetivo de la Corte Constitucional no reside, en efecto, en la

tenuta della priorità costituzionale indicata nella sent. 269/2017', en esta Rivista 2018, respectivamente 520 y ss., 530 y ss., 861 y ss.

${ }^{34}$ Sent. Cort. Cost. 49/2015.

${ }^{35}$ Cfr. Sent. Cort. Cost. 49/2015, que ha identificado una serie de índices idóneos a delimitar, en la perspectiva del Derecho interno, una jurisprudencia consolidada: la relación entre el principio afirmado en la concreta decisión y las orientaciones tradicionales de la jurisprudencia europea; los eventuales puntos de diferencia, o incluso de comparación,ante otras decisiones del TEDH; la subsistencia de opiniones disidentes; la circunstancia de que las decisiones dictadas por una sección simple y no por la Gran Cámara; la falta de consideración, por parte del juez europeo, de las peculiaridades del ordenamiento nacional. Para una reciente (y idiscutible?) aplicación de estas referencias cfr. Sent. Cort. Cost. 120/2018, que ha abierto la posibilidad, para los miembros de las fuerzas armadas, de constituir asociaciones profesionales con carácter sindical.

${ }^{36} \mathrm{El}$ procedimiento piloto se ha formalizado en el art. 61 del Reglamento del TEDH, y se adopta en el caso en el que se encuentre un problema estructural o sistémico en el ordenamiento nacional. Después de la adopción de la sentencia piloto, el Tribunal puede posponer todos los recursos a la espera de que el Estado adopte las medidas reparatorias indicadas.

${ }^{37}$ Por otra parte, ya en la Sent. Cort. Const. 301/2009 la Corte constitucional había confirmado que «l'apprezzamento della giurisprudenza europea consolidatasi sulla norma conferente va operato in modo da rispettare la sostanza di quella giurisprudenza».

${ }^{38}$ RUGGeRI, A., 'Fissati nuovi paletti alla consulta a riguardo del rilievo della Cedu in ambito interno. A prima lettura di Corte cost. n. 49 del 2015", Diritto penale contemporaneo, 2/2015, p. 330.

${ }^{39}$ Así BIGNAMI, M., 'Le gemelle crescono in salute: la confisca urbanistica tra costituzione, cedu e diritto vivente", en Diritto penale contemporaneo, 2/2015, p. 290, crítico con esta perspectiva, sin embargo, REPETTO, G., "Vincolo al rispetto del diritto CEDU "consolidato": una proposta di adeguamento interpretativo", Rivista AIC, 2015, n. 3, p. 414, nt. 10.

${ }^{40}$ Como ha objetado ZaGREBELSKY, V., "Corte cost. n 49 del 2015, giurisprudenza della Corte europea dei diritti umani, art. 117 Cost., obblighi derivanti dalla ratifica della Convenzione", Osservatorio costituzionale, mayo 2015; SORRENTI, G., "Sul triplice rilievo di Corte cost., sent. n. 49 del 2015, che ridefinisce i rapporti tra ordinamento nazionale e Cedu e sulle prime reazioni di Strasburgo", Forum di Quaderni costituzionali; TEGA, D., ''La sentenza della Corte costituzionale n. 49 del 2015 sulla confisca: «il predominio assiologico della Costituzione sulla CEDU»”, Quad. cost., 2015, pp. 400 y ss. 
reinterpretación de los institutos convencionales en el sistema de origen, con el objeto de una colonización soberanista del ordenamiento internacional; las condiciones impuestas por el Constitucional ofrecen, más bien, una legítima y necesaria transposición de los conceptos jurídicos convencionales en el Derecho nacional, en función de una gradación de eficacia de preceptos provenientes de un ordenamiento distinto $-\mathrm{y}$ derivado- del ordenamiento estatal $^{41}$.

Sin lugar a dudas es cierto, como ha afirmado recientemente el TEDH en una decisión donde parece que da réplica a la Corte Constitucional, que las sentencias de Estrasburgo tienen «todas el mismo valor jurídico» con independencia de la formación del colegio (Gran Cámara o sección) que las dicte ${ }^{42}$. Esta afirmación, sin embargo, sólo tiene valor en el exclusivo ámbito del sistema convencional y, por tanto, en relación con lo dictado específicamente contra el Estado contrayente; en otros términos, el dictum no implica por sí mismo una necesaria eficacia general y erga omnes, para todos los ordenamientos nacionales, por la singular decisión convencional.

Si este fuera el significado de la afirmación, el TEDH no sólo traicionaría su función subsidiaria, sino que asumiría también el cariz -nada tranquilizador- del «mite civilizzatore delle nazioni» ${ }^{43}$ - de una institución que aspira, en nombre de un abstracto orden público internacional, a imponer un monismo universal que niega el pluralismo constitucional de los Estados contrayentes.

\section{EL LÍMITE AXIOLÓGICO. LA NATURALEZA RESIDUAL Y RECESIVA DE LA INTERPRETACIÓN CONVENCIONALMENTE ORIENTADA.}

La sentencia de la Corte Constitucional n. 49 de 2015 no se limita, sin embargo, a definir el peso o la fuerza gravitacional de la jurisprudencia del TEDH sobre el juez nacional en su obra de adecuación del ordenamiento interno al Convenio. Va más allá, hasta traducir el límite del respeto de las disposiciones constitucionales (por parte del

\footnotetext{
${ }^{41}$ Para una lectura conciliadora de esta decisión, coherente con los mecanismos típicos de un sistema multinivel v. MARTINICO, G., 'Corti costituzionali (o supreme) e disobbedienza funzionale", en Dir. pen. cont. 2015 , p. 316.

${ }^{42}$ STEDH, GIEM AND OTHERS c. Italia de 28 de junio de 2018, sobre la cual REPETTO, G., 'I no che aiutano a crescere: confisca per lottizzazione abusiva e diritto CEDU «consolidato» dopo Punta Perotti bis", en Quad. cost. 2018, pp. 722 y ss. En particular, v. la "interpretación auténtica" de la decisión dada en la n. 96 de la opinión del Juez Pinto de Albuquerque.

${ }^{43}$ Era esta la función que el colonialismo eurocéntrico atribuía al Derecho internacional del siglo XIX, según la eficaz reconstrucción de KosKenNIEMI, M., Il mite civilizzatore delle nazioni. Ascesa e caduta del diritto internazionale 1870-1960, Roma-Bari, 2012.
} 
CEDH y, por ende, de su ley de ejecución ${ }^{44}$ ) del plano de las fuentes al de las relaciones entre actividades interpretativas, moviéndose de la estática de las disposiciones a la dinámica de las normas.

Ya la sent. const. n. 31717 de 2009, al introducir el concepto de la «máxima expansión de las garantías», había afirmado que la comparación entre quantum de tutela ofrecido por la jurisprudencia del TEDH y las disposiciones constitucionales se debería traducir en una «ponderación con otros intereses constitucionalmente protegidos, esto es con otras normas constitucionales, que a su vez garantizan derechos fundamentales (...) afrectados por la expansión de una tutela singular [cursivas añadidas]». Como la Corte Constitucional se preocupará de especificar más adelante, la comparación entre sistema convencional y ordenamiento constitucional no se realiza con referencia a la medida de la concreta situación subjetiva en cuestión, cuanto al sistema completo de los intereses constitucionales $^{45}$ : la integración inter-ordinamental de las tutelas no implica una valoración aislada de las normas del $\mathrm{CEDH}$, valoración que por el contrario «debe realizarse con referencia al sistema» de «todos los derechos y principios relevantes, constitucionales y supranacionales, considerados en su totalidad» ${ }^{46}$.

En este sentido, el vínculo preceptivo de la jurisprudencia del TEDH, y de la consecuente actividad hermenéutica que el juez ordinario desarrolla, a partir de la misma, sobre la disposición legislativa, opera sólo allí donde esta última no encuentre justificación en la necesidad de tutelar un bien o un valor de rango constitucional.

En otros términos, la obligación, que pesa sobre el juez ordinario de interpretar el Derecho interno en sentido conforme al $\mathrm{CEDH}$, está «subordinada a su obligación prioritaria de adoptar una lectura constitucionalmente conforme, ya que este modo de proceder refleja el predominio axiológico de la Constitución sobre el CEDH»: la interpretación conforme al Convenio cede el paso siempre que se pueda dar una lectura coherente con los principios constitucionales de la disposición legislativa.

Este particular límite axiológico ${ }^{47}$ da lugar a un dique ulterior a la operatividad de la interpretación convencionalmente orientada. El juez ordinario deberá constatar que la interpretación ortopédica no traspase el texto de la ley, traduciéndose quizá en una aplicación directa del Convenio, y deberá comprobar que, ante la imposibilidad de plasmar

\footnotetext{
${ }^{44}$ Así, expressis verbis, la Sent. Cort. Cost. 309/2011 que especifica lo afirmado en las "gemelas".

${ }^{45}$ Sent. Cort. Const. 264/2012.

${ }^{46}$ Cfr. Sent. Cort. Const. 170/2013.

${ }^{47}$ Así lo define Viganò, F., '’Il giudice penale...cit'”, p. 661.
} 
directamente el material convencional, el principio de derecho enunciado por el TEDH se inserte en una jurisprudencia consolidada o se haya dictado en un caso piloto; en definitiva, deberá valorar que la interpretación convencionalmente orientada no postergue un interés de rango constitucional, contrastando con una interpretación constitucionalmente conforme de la disposición.

De estas consideraciones se derivan al menos dos corolarios: la interpretación convencionalmente orientada tiene naturaleza residual, en el sentido de que la misma opera sólo allí donde no se sobrepasen los límites enunciados anteriormente. Incluso ante una laguna normativa, el juez ordinario no podrá recurrir a la interpretación convencionalmente orientada: en primer lugar, porque no le está permitido aplicar directamente el Convenio Europeo, tal como lo vive el juez de Estasburgo incluso en su dimensión "viviente"48; en segundo lugar porque, en todo caso, el principio de derecho elaborado por el TEDH debe quedar sometido a un específico test de compatibilidad constitucional, operando sólo allí donde ningún valor o interés de rango constitucional se oponga. Como regla sobre la interpretación, entonces, la interpretación convencionalmente orientada es por su propia naturaleza recesiva, está constreñida y debe ceder el paso en todos aquellos casos en los que pueda darse una interpretación constitucionalmente conforme de la disposición legislativa.

A la interpretación convencionalmente orientada, entonces, le queda la eminente función persuasiva en clave de consolidación de una determinada interpretación, por ejemplo para remarcar la conformidad con la Constitución de una determinada disposición o, viceversa, para manifestar al Juez constitucional su legitimidad constitucional por violar el sistema convencional.

\section{MUNDOS PARALELOS: EL ORDENAMIENTO CONSTITUCIONAL Y EL ORDENAMIENTO CONVENCIONAL COMPARADOS.}

El cuadro dibujado hasta el momento no parece destinado a cambiar de inmediato el futuro, como consecuencia de la entrada de en vigor del Protocolo adicional n. 16, que todavía no ha sido ratificado por Italia, el cual permitirá a las jurisdicciones superiores de los Estados contrayentes plantear al TEDH cuestiones que se refieran a la interpretación o

\footnotetext{
${ }^{48}$ A una conclusión similar llega MANES, V., "Metodo e limiti dell'interpretazione conforme alle fonti sovranazionali in materia penale", en L'interpretazione conforme... cit., p. 431. Contra Viganò, F., 'Il giudice penale... cit", pp. 655 y ss.
} 
a la aplicación de los derechos y de las libertades previstas por el Convenio ${ }^{49}$. A pesar de que no se le haya atribuido a este dictamen una eficacia vinculante, parece significativo que el órgano llamado a emitirlo sea la Gran Cámara, confirmando así el rol preminente que ésta asume en la formación del Derecho convencional.

Un último apunte. Se ha visto cómo el peculiar status de la interpretación convencionalmente orientada es debido, sobre todo, al rango interpuesto que el Convenio tiene en el ordenamiento interno. Sería sin embargo reductivo limitarse a tomar nota de la posición que la Carta convencional asume sin preguntarse sobre las razones teóricas que justifican la relación entre esta última y la Constitución.

La jurisprudencia constitucional ha facilitado al juez ordinario un hilo para salir del laberinto de las $\operatorname{Cartas}^{50}$; una brújula, quizá de compleja lectura y en continua evolución, que reposa sobre la regla áurea de la centralidad de la Constitución en el sistema interordinamental. Esta centralidad, recientemente confirmada por la Corte en referencia a la Carta de Derechos Fundamentales de la Unión Europea ${ }^{51}$, no es consecuencia de la mera supraordenación formal del texto constitucional -como querría una lectura eminentemente gradualística del ordenamiento- sino de la supremacía material de la Constitución sobre la normativa inferior a la misma o con origen externo. Como se evidencia del celebérrimo asunto Taricco y de la evocación de los contralímites ante el Derecho de la Unión Europea $^{52}$, la relación entre la Constitución y otras fuentes no puede, en efecto, reconstruirse exclusivamente sobre la base de una relación de validez o de mera derivación lógica, porque las normas constitucionales y el resto de normas no son «en absoluto términos homogéneos con el mismo valor» ${ }^{53}$. No es que el ordenamiento no exprese normas infraconstitucionales idóneas a desarrollar su identidad político-material ${ }^{54}$ : como ya había intuido Constantino Mortati, la materia constitucional excede el texto

\footnotetext{
${ }^{49}$ Sobre esta cuestión v. BUfFA, F., "Il Protocollo n. 16 addizionale alla Convenzione Edu è pronto per entrare in vigore", QuestioneGiustizia, publicado en www.questionegiustizia.it, y el volumen editado por LAMARQUE, E., La richiesta di pareri consultivi alla Corte di Strasburgo da parte delle più alte giurisdizioni nazionali: prime riflessioni in vista della ratifica del Protocollo 16 alla Convenzione europea dei diritti dell'uomo, Turín, 2015. Sobre las problemáticas conectadas a la posibilidad, para la Corte Constitucional, de recurrir a la solicitud de un dictamen PollicinO, O., "La Corte costituzionale è una "alta giurisdizione nazionale" ai fini della richiesta di parere alla Corte EDU ex Protocollo 16?”, ivi, pp. 37 y ss.

${ }^{50}$ Recuperando la feliz metáfora de MANES, V., Il giudice nel labirinto. Profili di intersezioni tra diritto penale e fonti sovranazionali, Roma, 2012.

${ }^{51}$ Cfr. Sent. Cort. Cost. 269/2017, sobre la cual se ha abierto un amplio debate en doctrina (v. las intervenciones que se recogieron en Consulta on-line en el epígrafe de la decisión).

${ }^{52}$ Cfr. Auto Cort. Cost. 24/2017, al que ha seguido la Sent. Cort. Const. 115/2018.

${ }^{53}$ Morrone, A., Il custode della ragionevolezza, Milán, 2001,p. 18.

${ }^{54}$ Aquello que una doctrina ha denominado el "contexto normativo" que concurre para componer el ordenamiento constitucional. Cfr. BARBERA, A., 'Costituzione... cit.', p. 276.
} 
constitucional, en el sentido de que hay preceptos que enriquecen, con una función promocional, el orden axiológico delineado por la $\mathrm{Carta}^{55}$. Estas normas, sin embargo, deben responder a la instancia de unificación dada por la Constitución, que admite la propia integración exclusivamente en los límites y en las formas, también institucionales, permitidos por la misma ${ }^{56}$.

Si la Constitución sitúa, por tanto, las coordinadas de una proceso de integración político-material, no se puede decir lo mismo del CEDH, cuya posición en el sistema de fuentes es el reflejo de las particulares finalidades del sistema convencional. Aunque no falte quien tienda a colocar las relaciones entre la Constitución y el CEDH (y la Carta de Derechos Fundamentales de la UE) en el ámbito de un "sistema de los sistemas", regido por la meta-norma de la máxima expansión de las garantías individuales ${ }^{57}$, el sistema convencional persiste como un ordenamiento internacional derivado. No es suficiente, en efecto, una lejana comunión axiológica, que encuentra las propias raíces en el milieu del constitucionalimo liberal-democrático, para asimilar los derechos tutelados por el Convenio a las situaciones subjetivas previstas por la Constitución. Ante el TEDH hay un demandante que «actúa uti singulus, no como ciudadano: la demanda no presupone el sinalagma (...) propiamente (...) sujeto a la relación de ciudadanía» ${ }^{58}$.

La jurisprudencia convencional es una «jurisdicción de los derechos individuales contra el Estado, en el sentido polémico de estar contra la idea de comunidad política ${ }^{59}$; un juez, por tanto, que opera caso a caso, en un espacio neutro, sustraído de los principios de representación política e-incluso- de separación de poderes ${ }^{60}$. El sistema convencional no conoce modalidades de distribución del poder similares a las que se contienen en la

\footnotetext{
${ }^{55}$ Mortati, C., "Costituzione dello Stato (dottrine dello Stato e Costituzione della Repubblica italiana)", en Enc. dir., XI, Milán, 1962

${ }^{56} \mathrm{Cfr}$. MEZZANOTTE, C., Corte costituzionale e legittimazione politica, Nápoles, 2014, p. 91. No es posible preguntarse, en esta sede, sobre las raíces de las teorías materiales de la Constitución. Sobre esta cuestión permítaseme remitirme, también para una perspectiva de institucionalización de las libertades constitucionales, a CARUSO, C., La libertà di espressione in azione. Contributo a una teoria costituzionale del discorso pubblico, Bolonia, 2013, pp.38 y ss. (y doctrina ivi citada), y también a CARUSO, C., RosSI, S., 'Settant'anni di Costituzione repubblicana. Un'introduzione', en CORTESE, F., CARUSO, C., Rossi, C., (ed.), Immaginare la Repubblica. Mito e attualità dell'Assemblea costituente, Milán, 2018,pp. 28 y ss.

${ }^{57}$ Cfr. RugGerI, A., '’L'interpretazione conforme... cit.', pp.161 y ss.

${ }^{58}$ Así Morrone, A., 'Crisi economica e diritti. Appunti per lo Stato costituzionale in Europa', Quad. cost., 2014, p.97, así como, si se quiere, CARUSO, C.,' L’hate speech a Strasburgo: il pluralismo militante del sistema convenzionale', Quad. cost., 2017, pp. 971 y ss.

${ }^{59}$ Morrone, A., ibidem.

${ }^{60}$ Sobre esta cuestión v. BIGNAMI, M., "'Ordinamento nazionale e Cedu. Impressioni al sole che è sorto", en www.questionegiustizia.it, p.7.
} 
segunda parte de la Constitución ${ }^{61}$, que va referida a una organización fundada también sobre el criterio de la mayoría y sobre el principio de la intermediación legislativa.

No solo. El Convenio Europeo se dirige a la proyección de un individualismo atomístico, el cual prescinde del cumplimiento, por parte del sujeto privado, de específicos deberes ante su comunidad de referencia y que, como tal, no se puede superponer al personalismo comunitario que se reconoce en el art. 2 Cost. ${ }^{62}$. Esta disposición no se limita a poner un dique a los abusos del poder público ante los individuos, según una lectura liberal (y negativa) de las libertades individuales (libertad de), sino que mira a tutelar al homme situé, la persona en sus concretas relaciones sociales y en su vida comunitaria. Por ello, la máxima expansión de las garantías, en el lenguaje adoptado por la Corte Constitucional, es muy distinta al individualismo libertario erigido en defensa de un sujeto privado abstracto, emancipado de las concretas relaciones sociales y de los conflictos típicos que caracterizan la sociedad pluralista y, como reflejo, los ordenamientos nacionales liberaldemocráticos.

La exaltación irreflexiva del CEDH y de su obra corre el riesgo de traducirse en una perniciosa ideología de los derechos, que traduce los derechos fundamentales en un eslogan, un cajón de sastre capaz de prevalecer por principio sobre cualquier instancia axiológica contraria. Precisamente por estas razones la Corte Constitucional ha subrayado que «la máxima expansión de las garantías» no es sinónimo del máximo nivel de tutela del concreto derecho subjetivo; el concepto se refiere, más bien, al razonable equilibrio del sistema normativo en su totalidad, donde deben encontrar adecuada composición las pretensiones uti singulus del ciudadano y los intereses públicos que permiten la existencia misma de una comunidad política edificada sobre (y con vista en) la realización de los valores constitucionales.

Tras los intereses públicos, en efecto, se encuentran iguales expectativas individuales de tutela, como emerge de la tormentosa causa de las conocidas como "pensiones suizas", donde está en juego, de forma no menos importante, la estabilidad general de las prestaciones de la Seguridad Social ${ }^{63}$ y, por tanto, al menos indirectamente, el interés de

\footnotetext{
${ }^{61}$ En este sentido v. también NisTiCÒ, M., ' 'Limiti e prospettive del circuito di tutela su più livelli dei diritti fondamentali', Costituzionalismo.it, 1/2018, pp. 264-265.

${ }^{62}$ Nos remitimos, a este respecto, a BARBERA, A., 'Art. 2', en BrAnCA, G., (ed.), Commentario della Costituzione, Principi fondamentali, art. 1-12, Bolonia, 1975, pp. 50 y ss.

${ }^{63}$ La cuestión, que incluye el distinto tratamiento que ha dado el TEDH y el Tribunal Constitucional a las leyes retroactivas, atiende a las modalidades de cálculo del tratamiento provisión social que corresponden a los ciudadanos italianos, aquellos trabajadores en Suiza, los cuales habiendo alcanzado, a título contributivo, las sumas exigidas por la legislación suiza y después al haber transferido sus contribuciones a Italia, exigen
} 
cada ciudadano a recibir las mencionadas prestaciones. En sede de teoría general, se ha evidenciado cómo los derechos suponen una suma cero, en el sentido de que «cualquier progreso en la tutela de un derecho encuentra su contrapeso, provoca así la regresión de la tutela de otro derecho o de otro interés» ${ }^{64}$. Esta afirmación es válida para los derechos tutelados en el Estado constitucional, mientras que queda desmentida en el espacio neutro del sistema convencional, donde las consecuencias de la tutela individual son siempre unidireccionales, traduciéndose, siempre y en todo caso, en una carga para el Estado contrayente.

La apertura internacional prescrita por el art. 11 y por el art. 117 Const. y la adhesión al CEDH -innovativo tratado que tutela al individuo ante (y contra) el Estado-incrementan los instrumentos para lograr el razonable equilibrio de las garantías, enriqueciendo los mecanismos de tutela del individuo y por tanto contribuyendo a corregir eventuales abusos, pero sin satisfacer las múltiples instancias que pueblan el Estado constitucional. El Convenio no es un ente con fines generales; sino, más bien, según las palabras del proprio $\mathrm{TEDH}$, es un «instrumento constitucional del orden público internacional» ${ }^{65}$, creado para que no se repitan, en el continete europeo, las atrocidades cometidas por los regímenes nazi-fascistas. La función subsidiaria, la aproximación casuística de la jurisdicción convencional, sus propias modalidades de composición, son consecuencia del particular telos que diferencia el Convenio, tratado de Derecho internacional no superponible, por su finalidad y estructura, a la Constitución republicana.

\section{BIBLIOGRAFÍA}

Barbera, A., 'Art. 2', en BrancA, G., (ed.), Commentario della Costituzione, Principi fondamentali, art. 1-12, Bolonia, 1975, pp. 50 y ss.

BARberA, A., "Costituzione della Repubblica italiana", en Enc. dir., ann. VIII, Milán, 2015, pp. 276 y 323.

BARTOLE, S., Interpretazioni e trasformazioni della Costituzione repubblicana, Bolonia, 2004, pp.166 y ss.

BERNARDI, A., 'Presentazione, Nei meandri dell'interpretazione conforme al diritto dell'Unione europea', en L'interpretazione conforme al diritto dell'unione europea. Profili e limiti di un vincolo problematico, Nápoles, 2015, p. XIII.

una pensión liquedada sobre la base a criterios retributivos. Cfr. Sents. Cort. Const. 172/2008, 264/2012, y, finalmente, de inadmisibilidad, la Sent. Cort. Const. 166/2017, que ha censurado el error por parte del juez remitente de la decisión del TEDH Stefanetti e altri c. Italia (2014). La Corte Constitucionla ha invitado al Legislador a intervenir en salvaguarde del "núcleo esencial del derecho lesionado".

${ }^{64}$ BIN, R., "70 anni dopo. Attualità e mitologie della Costituente. Discutendo le relazioni di Morelli, Faraguna, D’Amico e Saitto”, Immaginare la Repubblica, cit., p.172.

${ }^{65}$ STEDH Loizidou c. Turquía, 1995, § 75. 
BignAmi, M., 'Le gemelle crescono in salute: la confisca urbanistica tra costituzione, cedu e diritto vivente', en Diritto penale contemporaneo, 2/2015, p. 290.

BIN, R., 'L'interpretazione conforme. Due o tre cose che so di lei', en BERNARDI, A. (ed.), L'interpretazione conforme...cit., Nápoles, 2015, pp. 17 y ss.

BIN, R., 'Ordine delle norme e disordine dei concetti (e viceversa). per una teoria quantistica delle fonti del diritto", en Brunelli, G., Pugiotto, A., Veronesi, P., Scritti in onore di Lorenza Carlassare. Il diritto costituzionale come regola e limite al potere, vol. I., Nápoles, 2009, pp. 35 y ss.

BIN, R., 'L'applicazione diretta della Costituzione, le sentenze interpretative, l'interpretazione conforme della Costituzione alla legge", en La circolazione dei modelli e delle tecniche del giudizio di costituzionalità in Europa: Atti del XXI Convegno annuale, Roma 27-28 ottobre 2006:50 anniversario della Corte Costituzionale della Repubblica Italiana, Nápoles, 2010, p. 221.

BIN, R., "70 anni dopo. Attualità e mitologie della Costituente. Discutendo le relazioni di Morelli, Faraguna, D’Amico e Saitto”, Immaginare la Repubblica, cit., p.172.

BINDI, E., 'Divieto di bis in idem e doppio binario sanzionatorio nel dialogo tra giudici nazionali e sovranazionali', en Federalismi.it, 17/2018.

BIGNAMI, M., 'Ordinamento nazionale e Cedu. Impressioni al sole che è sorto', en www.questionegiustizia.it, p.7.

BUFFA, F., "Il Protocollo n. 16 addizionale alla Convenzione Edu è pronto per entrare in vigore", QuestioneGiustizia, publicado en www.questionegiustizia.it.

CARUSO, C., La libertà di espressione in azione. Contributo a una teoria costituzionale del discorso pubblico, Bolonia, 2013, pp.38 y ss.

CARUSO, C.,' L'hate speech a Strasburgo: il pluralismo militante del sistema convenzionale', Quad. cost., 2017, pp. 971 y ss.

CARUSO, C., Rossi, S., 'Settant'anni di Costituzione repubblicana. Un'introduzione', en Cortese, F., Caruso, C., Rossi, C., (ed.), Immaginare la Repubblica. Mito e attualità dell'Assemblea costituente, Milán, 2018,pp. 28 y ss.

CElOtTO, A., PISTORIO, G. Interpretazioni comunitariamente e convenzionalmente conformi, Giur. it. 2010, p. 1980.

CHESSA, O., 'Drittwirkung e interpretazione: brevi osservazioni su un caso emblematico', en Malfatti, E., Romboli, R., Rossi, E. (ed.), Il giudizio sulle leggi e la sua 'diffusione, Turín, 2002, pp. 420 y ss., 425.

CRISAFULLI, V., 'Disposizione (e norma)', en Enc. dir., vol. XII, Milán, 1964, pp.195 y ss.

EPIDENDIO, T., 'Riflessioni teorico-pratiche sull'interpretazione conforme', Dir. pen. cont., n.34,2012 , pp. 26 y ss.

GAETA, P., "Controllo di convenzionalità" e poteri del giudice nazionale: $i$ difficili approcci dell'ermeneutica giudiziale, draft, p. 9 y 10.

GUAZZAROTTI, A., ''Interpretazione conforme alla CEDU, proporzionalità e adeguatezza: il diritto di proprietà', en M. D'AMICO, B. RANDAZZO (ed.), Interpretazione conforme e tecniche argomentative, Atti del convegno di Milano svoltosi il 6-7 giugno 2008, Turín, 2009,p. 162.

KosKenNiemI, M., Il mite civilizzatore delle nazioni. Ascesa e caduta del diritto internazionale 1870-1960, Roma-Bari, 2012.

LAMARQUE, E., La richiesta di pareri consultivi alla Corte di Strasburgo da parte delle più alte giurisdizioni nazionali: prime riflessioni in vista della ratifica del Protocollo 16 alla Convenzione europea dei diritti dell'uomo, Turín, 2015.

LAMARQUE, E., 'Le relazioni tra l'ordinamento nazionale, sovranazionale e internazionale nella tutela dei diritti", en Dir. pubbl. 2013, p.788.

LuCIANI, M., ''Interpretazione conforme a Costituzione', Enc. dir., Ann., IX, Milán, 2016, pp. 442-445.

MANES, V., "Metodo e limiti dell'interpretazione conforme alle fonti sovranazionali in materia penale", en L'interpretazione conforme... cit., p. 431.

MANes, V., Il giudice nel labirinto. Profili di intersezioni tra diritto penale e fonti sovranazionali, Roma, 2012. 
MARANINI, G., 'Funzione giurisdizionale e indirizzo politico nella Costituzione', en Rass. parl., 1965 , pp. 538 y ss.

MARTINICO, G., 'Corti costituzionali (o supreme) e disobbedienza funzionale', en Dir. pen. cont. 2015, p. 316.

MEZZANOTTE, C., Corte costituzionale e legittimazione politica, Nápoles, 2014, p. 91.

MezzAnotTe, C., Il giudizio sulle leggi, I, Le ideologie del Costituente, Nápoles, 2014, pp.196197.

Modugno, F., 'Sul problema dell'interpretazione conforme a Costituzione: un breve excursus', Giur. it., 2010, p. 1963.

MORRONE, A., Il custode della ragionevolezza, Milán, 2001,p. 18.

MorRone, A., 'Crisi economica e diritti. Appunti per lo Stato costituzionale in Europa', Quad. cost., 2014, p.97.

MoRTATI, C., "Costituzione dello Stato (dottrine dello Stato e Costituzione della Repubblica italiana)", en Enc. dir., XI, Milán, 1962.

NisTiCÒ, M., "Limiti e prospettive del circuito di tutela su più livelli dei diritti fondamentali', Costituzionalismo.it, 1/2018, pp. 264-265.

PACE, A., ' 'I limiti dell'interpretazione «adeguatrice»", Giur. Costit., 1963, pp. 1070-1073.

PACE, A., 'Identità o differenza tra la questione di costituzionalità della norma e la questione di costituzionalità dell'interpretazione?', Giur. Costit., 1965, pp.1650 ss.

PACE, A., "'Sul dovere della Corte costituzionale di adottare sentenze di accoglimento (se del caso, «interpretative» e «additive») quando l'incostituzionalità stia nella «lettera» della disposizione", en Giur. Costit., 2006, pp. 3430-3431.

PEPE, F., 'La Corte costituzionale prende atto della metamorfosi del ne bis in idem europeo: fine della storia?', en esta Rivista 2018, pp. 520 y ss.

POLLICINO, O., "La Corte costituzionale è una "alta giurisdizione nazionale" ai fini della richiesta di parere alla Corte EDU ex Protocollo 16?”, ivi, pp. 37 y ss.

REPETTO, G., 'I no che aiutano a crescere: confisca per lottizzazione abusiva e diritto CEDU «consolidato» dopo Punta Perotti bis", en Quad. cost. 2018, pp.722 y ss.

REPETTO, G., "Vincolo al rispetto del diritto CEDU "consolidato": una proposta di adeguamento interpretativo", en questa Rivista, 2015, p. 414, nt. 10.

Romboli, R., 'Il giudizio di costituzionalità delle leggi', en ID. (ed.), Aggiornamenti in tema di processo costituzionale (1996-1998), Turín, 1999,p.202

RomBoli, R., "Vincolatività della interpretazione della Cedu da parte della Corte Edu e restituzione degli atti al giudice "a quo" in una pronuncia che mostra la difficile tenuta della priorità costituzionale indicata nella sent. 269/2017', en esta Rivista 2018, pp. 861 y ss.

RUGGERI, A., 'Fissati nuovi paletti alla consulta a riguardo del rilievo della Cedu in ambito interno. A prima lettura di Corte cost. n. 49 del 2015', en Diritto penale contemporaneo 2/2015, p. 330.

RUGGERI, A., 'L'interpretazione conforme e la ricerca del "sistema di sistemi" come problema", en L'interpretazione conforme... cit., pp.153-158, 161 y ss.

RUGGERI, A., 'Lo Stato costituzionale e le sue mutazioni genetiche', Quad. cost., 2014, p.845 y ss.

Ruotolo, M., 'Interpretazione conforme a Costituzione e tecniche decisorie della Corte costituzionale", en AA.VV., Scritti in onore di Alessandro Pace, Nápoles, 2012, p. 2478

RuOTOLO, M., 'Per una gerarchia degli argomenti dell'interpretazione', en Giur. Costit., 2006, , pp. 3418 y ss.

SERGES, G., 'Interpretazione conforme e tecniche processuali', ivi, 1977-1978.

SORRENTI, G., L'interpretazione conforme a Costituzione, Milán, 2006, p. 111

TRIPODO, A.F., 'Il nuovo volto del ne bis in idem convenzionale agli occhi del giudice delle leggi. Riflessi sul doppio binario sanzionatorio in materia fiscale", en esta Rivista 2018, pp.530 y s.

SORRENTI, G., "'Sul triplice rilievo di Corte cost., sent. n. 49 del 2015, che ridefinisce i rapporti tra ordinamento nazionale e Cedu e sulle prime reazioni di Strasburgo", en Forum di Quaderni costituzionali. 
TEGA, D., ''La sentenza della Corte costituzionale n. 49 del 2015 sulla confisca: «il predominio assiologico della Costituzione sulla CEDU»", en Quad. cost. 2015, pp. 400 y ss.

VIGANÒ, F., 'Il giudice penale e l'interpretazione conforme alle norme sovranazionali', en Corso, P., ZanetTI, E., Diritto processuale penale e profili internazionali. Diritto straniero e diritto comparato, en Studi in onore di Mario Pisani, Plasencia, 2010, p. 634, 649, 661, 665 y ss.

ZAGREBELSKY, V., 'Corte cost. n 49 del 2015, giurisprudenza della Corte europea dei diritti umani, art. 117 Cost., obblighi derivanti dalla ratifica della Convenzione", en Osservatorio costituzionale, 2015.

\section{JURISPRUDENCIA}

\section{Corte Constitucional Italiana}

Sent. Cort. Cost. 8/1956

Sent. Cort. Cost. 356/1996

Sent. Cort. Cost. 190/2000

Sent. Cort. Cost. 348/2007

Sent. Cort. Cost. 349/2007

Sent. Cort. Cost. 172/2008

Sent. Cort. Cost. 349/2007

Sent. Cort. Cost. 17/2009

Sent. Cort. Cost. 293/2009

Sent. Cort. Cost. 301/2009

Sent. Cort. Cost. 331/2009

Sent. Cort. Cost. 93/2010

Sent. Cort. Cost. 113/2011

Auto Cort. Cost. 150/2012

Sent. Cort. Cost. 264/2012

Sent. Cort. Cost. 170/2013

Sent. Cort. Cost. 49/2015

Sent. Cort. Cost. 221/2015

Auto Cort. Cost. 24/2017

Sent. Cort. Cost. 42/2017

Sent. Cort. Cost. 83/2017

Sent. Cort. Cost. 123/2017

Sent. Cort. Cost. 166/2017 
Sent. Cort. Cost. 269/2017

Sent. Cort. Cost. 43/2018

Sent. Cort. Cost. 77/2018

Sent. Cort. Cost. 115/2018.

Sent. Cort. Cost. 120/2018

\section{Tribunal Europeo de Derechos Humanos}

STEDH de 15 de abril de 2014, Stefanetti y otros c. Italia, apl. nos. 21838/10, 21849/10, 21852/10, 21855/10, 21860/10, 21863/10, 21869/10 and 21870/10

STEDH de 28 de junio de 2018, Giem y otros c. Italia, apl. nos 1828/06, 34163/07 and 19029/11

STEDH de 18 de diciembre de 1996, Loizidou v. Turquie, apl.n. 15318/89 